\title{
The re-configurable enterprise - dynamic behaviour in manufacturing systems
}

\author{
H. Kühnle, D. Markfort \\ Fraunhofer Institute Factory Operation and Automation \\ Sandtorstraße 22, 39106 Magdeburg, Germany \\ e-mail: kuehnle@iff.fhg.de, markfort@iff.fhg.de
}

\begin{abstract}
The development in the last few years highlights that fundamental and sustaining changes occur in industry. Globalisation, increasing customer demands, innovation and technology jumps and increasing complexity are signs for these changes.

This paper describes a new way to handle these changes. Today's companies need to migrate to re-configurable structures, which fulfil the requirements of adaptability, capability development, management of complexity, robustness and goal-orientation.

The concept of the re-configurable enterprise is one way to cope with today's fast turbulent environment. It has been developed by the Fraunhofer-Institute Factory Operation and Automation. The following paper describes three dimensions of the re-configurable enterprise, especially the structural dimension will be explained in more detail.
\end{abstract}

Keywords

Manufacturing, dynamic behaviour, re-configurable enterprise 


\section{INTRODUCTION}

The past was characterised by a stable industrial environment, but this has significantly changed in the last years. Signs of this new environment can be detected on many levels and are strongly related. Compared to the past three decades, particularly the complexity of the company's environment has increased nowadays. This increased complexity has led to an increased dynamic and chaotic behaviour of the environment. This development is called the "turbulent environment". The following table shows exemplary the development in product life cycles in different German industries (Pohl, 1996):

Table 1: Development of product life cycles in Germany

\begin{tabular}{lllllll} 
Engineering & Facility & Car & Machine & Electrical & Information & Chemistry \\
\hline 1970 & 13 & 11 & 12 & 12 & 11 & 11 \\
1990 & 9 & 7 & 7 & 5 & 5 & 5 \\
\hline
\end{tabular}

Beside the external complexity, the internal complexity is increasing too. Today's companies are highly complex systems, due to internationalisation and the reduction in the depth of vertical range of manufacture. Thus, new methods of control and management need to be applied.

Therefore, the enterprises are confronted with the tasks: How to compete in today's turbulent and complex environment and how to manage the internal complexity?

\section{BASICS OF THE RE-CONFIGURABLE ENTERPRISE}

Within the above described environment, the previous behaviour patterns, methods, and approaches (e.g. technology orientated basic strategies; organisational principles and structures, which are focused on repeated task fulfilment; processes based on long term forecasts and mechanical roles) do not lead to success anymore. Therefore, existing description frames do not suit anymore.

To overcome this problem, several models, e.g. Holonic manufacturing systems, Bionic manufacturing system, Virtual enterprise, Agile manufacturing, Learning organisation, Fractal company and Mass Customisation, have been developed in recent years. Though these models all try to cope with the new environment, they describe several levels of the enterprise and are different in their abstraction. The 
re-configurable enterprise combines several views on the future development of enterprises and manufacturing systems and is therefore better suited for dealing with the future.

The re-configurable enterprise is the advancement of the Fractal Company. The fractal company concept was mostly focused on the market and structural aspects. During the project "DYNAPRO", the Fraunhofer IFF extended the Fractal Company concept by special methods and instruments to implement dynamic structural behaviour. The Fractal Company is defined as an open system consisting of independently acting entities called fractals (Warnecke, 1993). These fractals are goal-oriented, self-similar, self-organised and self-optimised. They form a vital organism through dynamic organisational structures. Therefore, the fractal company concept is the basis for the re-configurable enterprise.

The re-configurable enterprise extends the theoretical core of the fractal company by including strategic aspects and network competencies. Thus, it includes the market (environment), the structure, the strategy and the competencies to operate and to manage networks. It is expected to be the dominant form of manufacturing enterprise in times of unpredictable competitive challenges and within a rapidly and chaotically changing global business environment.

The three main abilities of the re-configurable enterprise are defined as follows. It is on one hand able to adapt actively itself with own resources to fast and unpredictable changing tasks (ability to adapt). On the other hand, the reconfigurable enterprise is able to develop itself in a self-driven manner (ability to develop) under relatively constant constraints. The ability to develop is in opposition to adaptability not reaction-driven. It is based on chance-driven actions. Furthermore, the re-configurable enterprise is able to induce turbulence within separated market segments, which will cause considerable advantages compared to competitors.

The Fraunhofer IFF has identified four highly interlocked dimensions that are important for the re-configurable enterprise. Each dimension is based on several key factors. The four dimensions are illustrated in the next figure. 


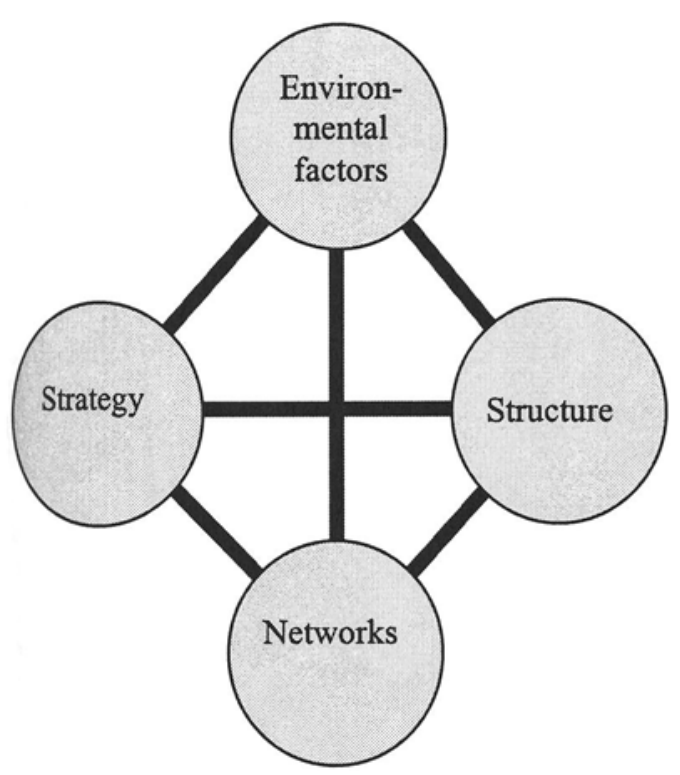

Figure 1: Dimensions of the re-configurable enterprise.

The following chapter will describe the aspects strategy, structure and networks. Environmental factors will be left out for this would go beyond the scope of this article.

\subsection{Strategy}

The strategy of a re-configurable enterprise is mainly based on the key factors growth strategies and development strategies. Growth strategies aim at a sustained, profitable growth. The focus of future growth strategies is mainly on new or unknown markets and new or unknown products. The sustained profitability can be realised by strategic product development, strategic product differentiation, strategic product specialisation, dominant design, service as a product, service as a carrier and system solutions.

Development strategies support the capability to develop in self-driven manner. They are based on company's vision, the corporate identity and space of activities for the employees.

\subsection{Structure}

The structure of the re-configurable enterprise has to be highly dynamic. The principles of the structure - self-similarity, self-organisation and self-optimisation are based on the fractal company concept and enable the structure to adapt to 
changes and to develop itself in a self-driven manner. These principles are supported by the following seven requirements for dynamic structural behaviour.

\section{Goal-orientation.}

Goal-orientation is the first step for improving the adaptability and ability to develop of the enterprise. Goal-orientation is based on a goal system that is communicated to the total work force. The goal-orientation starts with the company's vision, which aims at market-oriented alignment of the company. To meet this vision, an enterprise overall goal system has to be implemented.

The subordinated goals then are grouped in the enterprise goal system. These goals are defined for single organisational units. All business activities aim at these goals.

There is goal agreement instead of definitions. To meet the goal agreement, several key performance indicators, e.g. throughput time, delivery time, are monitored continuously.

The navigation is based on decentralised controlling, self-controlling feedback loops and management by objectives (Markfort, 1997).

\section{Transparency.}

Transparency means that the processes and goals are transparent for the total work force. As stated above, goals are transformed to key performance indicators. These are displayed and discussed regularly with the work force. This regular update on the company's goals has proven to be very effectual, most companies do not realise how important it is to communicate the goals to everyone. Therefore, frictional losses can be avoided through information sharing and advantages at reaction times can be utilised as result of direct conversation. High transparency allows to react rapidly to changes and it supports entrepreneurial thinking of the total work force. Furthermore, transparency forces also a continuos monitoring of key indicators.

\section{Congruence.}

One characteristic of dynamic structures is the delegation of responsibility and competence into single organisational units. The necessary activities to fulfil the tasks will be assigned to the proper organisational structure. Experience has shown, that many companies are not organised according to this principle. Especially matrix organisations are very delicate in this matter, since it is most times not quite clear, who is responsible for what. But also other forms of organisation have to take congruence into consideration. Congruence is not met e.g. when there is a program manager who is responsible for the production (his goal could be the throughput), but who has no influence on the logistics within his production. Therefore the assignment of responsibility, the goals related to this and the assigned competence have to looked at very carefully. With a congruent assignment, the operational level of the company is able to react fast, flexible and competent in sudden dynamic situations. 
Space of activities.

Space of activities is realised, if goals are clearly agreed and the necessary resources to achieve the goals are available, this deriving form the assigned competence. For that purpose, a high autonomy and freedom of decisions (congruence) about the use of resources (machines and employees) inside the space of activities must be created. In practice this means that the superior should not care how a goal is achieved, only that it is achieved. This space of activities increases the motivation and participation of the work force and is highly influenced by style of management. The style of management has to shift from the command \& control philosophy of modern industrial corporation to one of leadership, motivation, support, and trust.

\section{Change-Competence.}

Change-competence requires entrepreneurial thinking and acting. For that purpose, employees must be able to judge the situations coming up and they must have the possibility to influence these situations. Contradictions between company's goals and the goals of employees have to be avoided.

The management has to focus at knowledge. A high degree of knowledge reduces the reaction time and enables the employee to develop himself in a self-driven manner. Knowledge is interlocked with life-long learning and training. To guarantee the adaptability and ability to develop, the re-configurable enterprise fulfils the demands on information and knowledge management (e.g. extended professional, methodological and social competencies, transparent process, transparent knowledge, principle of retrieving information by those in need of it, quick and requirement-orientated information generation, free communication, visualisation of goals, state and results and active development of knowledge/learning processes).

\section{Performance-orientation.}

In order to achieve a common performance orientation the single workers wages have to be linked to the overall performance, which is measured by the key performance indicators. This is done by e.g. adding a bonus to each workers wage if his organisational unit meets all it's agreed goals. Experience has shown, that bonuses should be linked to the same key performance indicators which are valid for the entire organisational unit. This eases the understanding of goal and performance orientation (Leidig, Förster 1998).

\section{Basis flexibility.}

Flexible technology concepts and concepts of flexible staff increase the ability to react fast on dynamic situations and to act chance-oriented. These concepts should not be rigid and fixed for a longer time. The concepts for flexible technique and flexible staff deployment must be aimed at the requirements concerning capability of dynamics of the company, e.g. incoming orders. 


\subsection{Networks}

Beside the internal structural re-configuration, the re-configurable enterprise is also able to operate and manage work within networks or supply chains. Forming and dissolving teams within a single enterprise has a lot of similarities to forming and dissolving networks between different companies and will result in similar problems. Networks will benefit the enterprise, if all participants share common goals (Kühnle, Schnaufer, Brehmer 1999).

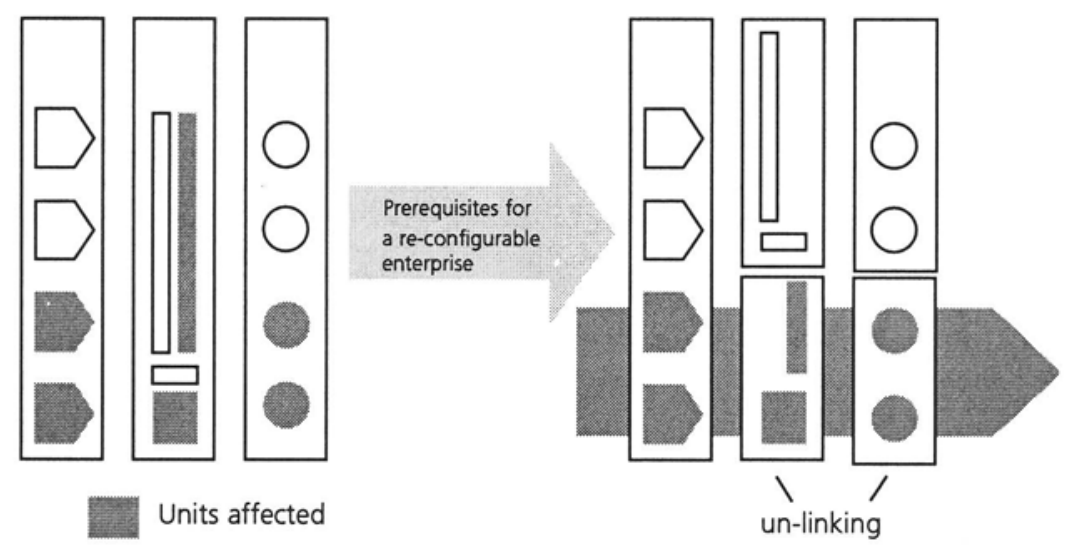

Figure 2: The re-configurable enterprise within a network

\section{CONCLUSION}

As it was mentioned, the re-configurable enterprise is based on four dimensions. The structural aspect of the re-configurable enterprise was explained in detail.

One can say, the re-configurable enterprise based on the four dimensions will be the dominant form of manufacturing enterprise in times of unpredictable competitive challenges and within a rapidly and chaotically changing global business environment. It can summarised in the following sentence: "The reconfigurable enterprise makes profit even in times of turbulent markets.

\section{REFERENCES}

Hartmann, M. (1997) Dynapro II - Erfolgreich produzieren in turbulenten Märkten, Logis Verlag, Stuttgart

Kühnle, H.; Schnauffer H.-G.; Brehmer, N. (1999): Kooperation nach fraktalen Prinzipien, in: Zeitschrift für wirtschaftlichen Fabrikbetrieb, 94, 132-135, C. Hanser Verlag, München

Leidig, F.; Förster, T. (1998) Dynamische Prozeßorganisation, in: Dynapro III Erfolgreich produzieren in turbulenten Märkten, Logis Verlag, Stuttgart 
Markfort, D. (1997) Die Zieldiskussion, in: Hartmann, M. (1997) Dynapro II Erfolgreich produzieren in turbulenten Märkten, Logis Verlag, Stuttgart

Pohl, A. (1996) Leapfrogging bei technologischen Innovationen, Gabler Verlag, Wiesbaden

Warnecke, H.-J. (1993) The Fractal Company, Springer Verlag, Berlin, Heidelberg, New York

\section{BIOGRAPHY}

\section{Hermann Kühnle}

Education

1972 - 1979 Mathematics, physics and computer science at the University of Stuttgart

$1979 \quad$ Diploma examination

1987 Obtaining of a doctorate, Doctor of Engineering science, University of Stuttgart

1989-1994 Assistant Professor MBA Production-Information Systems Stuttgart

Professional Background

$1982 \quad$ Head of Group "Material Flow", Fraunhofer IPA

1986 - 1991 Head of Department, Fraunhofer IPA

1987 - 1994 Manager of CIM-Technology transfer centre, University of Stuttgart

1994 -

\section{Dirk Markfort}

Magdeburg, as well as Executive Director of the Fraunhofer IFF, Magdeburg

\section{Education}

1987 - 1995 Mechanical Engineering at the University of Karlsruhe

1995 Diploma examination

1992 - 1994 Mechanical Engineering at the Arizona State University

$1994 \quad$ Master of Science

Professional Background

1995

Scientist at the Fraunhofer IFF

1998

Head of Department 